\title{
APPLICATIONS OF BRAZILIAN ILLITE-KAOLINITE IN NATURAL AND INTERCALATED FORMS AS ADSORBENTS TO REMOVAL OF ZINC FROM AQUEOUS SOLUTIONS: KINETIC AND THERMODYNAMIC STUDIES
}

\author{
R. A. R. DA SILVA', D. J. L. GUERRA ${ }^{1 *}$ \\ (I) Department of Mineral Resources, Federal University of Mato Grosso, DRM-ICET-UFMT, Cuiabá, Mato Grosso, Brazil 78060900. \\ (Received: June 28, 2012 - Accepted: March 12, 2013)
}

\begin{abstract}
The capability of natural and modified-Illite/kaolinite for zinc adsorption from aqueous solution was investigated in the present paper. The new hybrid material was composed of the natural clay using the intercalation process with dimethyl sulfoxide. The objective of this study was to examine the adsorption behavior of Brazilian phyllosilicate sample and hybrid material, towards a divalent metal has been studies by a batch technique. The phyllosilicate sample and hybrid material were characterized by x-ray diffractometry (XRD) and elemental analysis. The Avrami, Lagergren, Elovich, and Intra-particle diffusion models for adsorption isotherms were applied for analyses experimental data in order to determine the adsorption capacity to form a monolayer and the constant related to the adsorption intensity. The adsorption equilibrium was established in 140 minutes for natural and 120 minutes for modified clay. The maximum number of moles adsorbed was determined to be 12.55 and $22.89 \mathrm{mmolg}^{-1}$ for systems $\mathrm{Zn}^{2+}$ (kaolinite/ilite) and $\mathrm{Zn}^{2+}$ (kaolinite/ilite + dimethyl sulfoxide), respectively.
\end{abstract}

Keywords: Kaolinite/illite; Adsorption; Zinc; Kinetic; Thermodynamic.

\section{INTRODUCTION}

The pollutant by heavy metals was obtained widespread attention in the current researcher in the recent decades. Elevated volumes of aqueous effluents contaminated with heavy metal as zinc are generated by industrial activity. Industrial effluents containing toxic metals need to be treated before being delivered to environmental ${ }^{1,2}$.

Clays, acidified clay, pillared clay, and organoclays have been employed in a large number of investigations for removal toxic metals and other contaminants as dyes from the effluents. The use of adsorption process for removal of contaminant species on clay surfaces has received considerable attention $^{3,4}$. Important study reported adsorption of trivalent metal cadmium on illite while bentonite in the decontamination for aqueous effluent contaminated by zinc ${ }^{5}$, The kinetics studies of the removal of $\mathrm{Pb}$ (II) and other divalent metals by sepiolite clay sample was also studied by Brigatti et al. $(2000)^{6}$. Utilization of kaolinite clay for the removal of significant concentrations of $\mathrm{Cu}(\mathrm{II}), \mathrm{Ni}(\mathrm{II})$, $\mathrm{Co}(\mathrm{II})$, and $\mathrm{Mg}(\mathrm{II})$ was widely researched ${ }^{7}$. Adsorption process has been found to be an economic alternative with satisfactory potential for elimination and recovery of toxic metals from aqueous medium.

The present work was undertaken to investigate the feasibility of using an interstratified kaolinite/ilite clay sample, in two forms: natural and intercalated with dimethyl sulfoxide (DMSO), for removal divalent metal zinc from aqueous medium by adsorption. The kinetic of adsorption was investigated with variation of contact time and thermal effects involved in adsorption process were obtained with Van't Hoff correlation. The natural and chemical aspects related to the hybrid material composition with DMSO on the structure clay were presented in this study. The natural clay and new hybrid material were able to remove $\mathrm{Zn}^{2+}$ ions from aqueous medium, based on error function values the data were best fitted to the pseudo second-order model.

2. Materials and methods

2.1. Raw material and reagents

The clay sample used in this investigation was obtained from Capinópolis area, Minas Gerais state, Southeast of Brazil. A natural interstratified sample, named KA-IL, with less than $2 \mathrm{~mm}$ particles, was separated by sedimentation. The natural silicate sample was activated in a stream of dry nitrogen by heating at $423 \pm 1 \mathrm{~K}$ for approximately $10 \mathrm{~h}$ and used immediately.

Reagent grade solvents were used. The compound dimethyl sulfoxide (DMSO) $\left[\left(\mathrm{CH}_{3}\right)_{2}-\mathrm{S}=\mathrm{O}\right]$ was used without purification. Other chemicals such as methanol and ethanol were of reagent grade. Stock standard solution 5000.0 $\mathrm{mgdm}^{-3}$ of zinc chloride $\left(\mathrm{ZnCl}_{2}\right)$ was obtained from Sigma Chemical Co, USA. Doubly distilled deionized water (DDW) was used for the preparation of solutions, wherever required. Solutions of zinc were prepared from suitable serial dilution of the stock solution in DDW.

2.2. Functionalization of kaolinite/illite clay

The functionalized hybrid material was synthesized in concordance with methodology developed by Avila et al. (2009) ${ }^{8}$ : approximately $20 \mathrm{~g}$ of KA-IL clay was added to the DDW and the stirring was continued for $50 \mathrm{~min}$. During this time period the DMSO was added drop-wise to form the final hybrid material, which is called KA- $\mathrm{IL}_{\mathrm{DMSO}}$. After addition of intercalated agent, the resulting mixture was further stirred for $20 \mathrm{~h}$ at $291 \pm 1$ degree $\mathrm{K}$. At the end of the above process, the material was centrifuged, washed with DDW/methanol/ ethanol and dried at $335 \pm 1 \mathrm{~K}$ for $30 \mathrm{~h}$.

2.3. Batch organofunctionalization study

The adsorption experiments were performed by a batchwise method, i.e. by suspending $20.0 \mathrm{mg}$ of each material in an aqueous solution $\left(25.0 \mathrm{~cm}^{3}\right)$ of the divalent zinc at concentrations varying from 0.20 to $5.50 \mathrm{mmoldm}^{-3}$, under orbital stirring for $24 \mathrm{~h}$ at $298 \pm 1$ degree $\mathrm{K}^{9,10}$. The clay types were separated by centrifugation and supernatant solutions were carefully transferred to glass flasks to determine the concentrations of zinc in aqueous medium. The final concentrations of the zinc ions were determined using a Perkin Elmer Flame Atomic Absorption (AA) Spectrometer model Analyst 200 operating with an air-acetylene flame and a zinc cathode lamp $\left(1_{\text {Zn(II) }}=213.86 \mathrm{~nm}\right.$ and analytical line $=307.59 \mathrm{~nm})$. The zinc adsorption capacities $\left(\mathrm{N}_{\mathrm{f}}\right)$ of the clays were calculated as follows (Eq. 1), for a series of isotherms, revealed that the adsorption process conforms to the equilibrium models. The isotherm equations corresponding to the Langmuir, Freundlich, and Sips models are presented in Table 1. The kinetic equations corresponding to the Avrami, pseudo-firstorder, pseudo-second-order, Elovich, and Intra-particle diffusion models ${ }^{11}$ are given in Table 1.

Table 1: Kinetic adsorption models.

\begin{tabular}{|c|c|}
\hline Adsorption models & Nonlinear equations \\
\hline \multicolumn{2}{|c|}{ Isotherms equilibrium models } \\
\hline Langmuir & $\mathrm{N}_{\mathrm{f}}=\frac{\mathrm{N}_{\mathrm{L}} \mathrm{K}_{\mathrm{L}} \mathrm{C}_{\mathrm{S}}}{1+\mathrm{K}_{\mathrm{L}} \mathrm{C}_{\mathrm{S}}}$ \\
\hline Freundlich & $\mathrm{N}_{\mathrm{f}}=\mathrm{K}_{\mathrm{F}} \mathrm{C}_{\mathrm{S}^{\frac{1}{\mathrm{n}_{\mathrm{F}}}}}$ \\
\hline Sips & $\mathrm{N}_{\mathrm{f}}=\frac{\mathrm{N}_{\mathrm{S}} \mathrm{K}_{\mathrm{S}} \mathrm{C}_{\mathrm{S}}^{\frac{1}{n_{\mathrm{s}}}}}{1+\mathrm{K}_{\mathrm{S}} \mathrm{C}_{\mathrm{S}^{\frac{1}{n_{\mathrm{S}}}}}^{\frac{1}{n^{2}}}}$ \\
\hline \multicolumn{2}{|c|}{ Kinetic models } \\
\hline Avrami & $\mathrm{N}_{\mathrm{t}}=\mathrm{N}_{\mathrm{E}}\left[1-\exp \left[-\left(\mathrm{k}_{\mathrm{AV}} \mathrm{t}\right)\right]^{\mathrm{n}_{\mathrm{AV}}}\right]$ \\
\hline Pseudo-first-order & $N_{t}=-N_{E}\left[1-\exp \left(-k_{f} t\right)\right]$ \\
\hline Pseudo-second-order & $\mathrm{N}_{\mathrm{t}}=\frac{\mathrm{N}_{\mathrm{E}}{ }^{2} \mathrm{k}_{\mathrm{s}} \mathrm{t}}{1+\mathrm{k}_{\mathrm{s}} \mathrm{N}_{\mathrm{E}} \mathrm{t}}$ \\
\hline
\end{tabular}




$$
\mathrm{N}_{\mathrm{t}}=\frac{\mathrm{N}_{\mathrm{i}}-\mathrm{N}_{\mathrm{e}}}{\mathrm{m}}
$$

where $\mathrm{N}_{\mathrm{i}}(\mathrm{mmol})$ is the initial number of moles of $\mathrm{Zn}^{2+}$ added to the surface of adsorbent, $\mathrm{N}_{\mathrm{e}}(\mathrm{mmol})$ is the amount remaining after the equilibrium of adsorption reactions, and $\mathrm{m}(\mathrm{g})$ is the mass of the adsorbent. Profiles of the obtained adsorption isotherms were represented by the number of moles per gram interstratified types, $\mathrm{N}_{\mathrm{t}}\left(\mathrm{mmolg}^{-1}\right)$, versus the number of moles at equilibrium per volume of solution of zinc, $\mathrm{C}_{\mathrm{S}}\left(\mathrm{mmoldm}^{-3}\right)$.

2.4. Analytical Procedure

The elemental analysis $(\% \mathrm{C}, \% \mathrm{H}$, and $\% \mathrm{~S})$ was determined on a Perkin Elmer 2400 Series II microelemental analyzer, and at least two independent determinations were performed for natural and modified bentonite samples.

X-ray diffraction (XRD) of the clay samples was obtained with a Philips 3020 Goniometer with PW 3710 Controller using $\mathrm{Cu}$ Ka radiation at $40 \mathrm{kV}$ and $20 \mathrm{~mA}$ and $\mathrm{Ni}$ filter.

\section{RESULTS AND DISCUSSION}

\subsection{Characterization of materials}

In these formed 2:1 silicate structures the organic part is distributed inside the interlayer lamellar cavity of interstratified illite-kaolinite (I-K) and the percentages of carbon, hydrogen, and sulfur content are listed in Table 2, with the integrity of the organic molecules being present in the dioctahedral 2:1 structure of $\mathrm{I}-\mathrm{K}$ confirmed from the calculated $\mathrm{C} / \mathrm{S}$ ratios ${ }^{12}$. Based on the analytical data for KA-IL and one organic-inorganic material, the density of these pendant organic molecules immobilized on the tetrahedral silica layer of the phyllosilicate can be calculated. Thus, the precursor DMSO agent grafted onto interstratified clay gave an amount of $7.447 \mathrm{mmolg}^{-1}$. In principle, this small pendant molecule density should be expected as a consequence of its large volume, which could cause a degree of hindrance to impede the reaction.

X-ray diffraction patterns of the KA-IL and KA- $\mathrm{IL}_{\mathrm{Dmso}}$ samples are given in Figs. 1a and 1b, respectively. Interstrafied illite-kaolinite (I-K) as principal clay minerals and quartz $(\mathrm{Q})$ and feldspar (F) as impurities or accessory clay minerals, the raw clay sample is constituted by the conjunct of these minerals ${ }^{13}$. The components of $\mathrm{I}-\mathrm{K}$ were concentrated in the fine size fraction $(<2.0$ mess); therefore, an important decrease of quartz and feldspar components was observed after organofunctionalization process, principally in the sample organofunctionalized by DMSO. In the Interstrafied fraction of KA-IL, the kaolinite clay was the predominant mineral and illite was the mineral with minor perceptual (Fig. 1b). The Bragg equation was used for determination of $\mathrm{d}_{001}$ values and used to calculate the remaining reflections ${ }^{14}$. The 001 peak of the illite- kaolinite component of the KA- $\mathrm{IL}_{\mathrm{Dys}}$ sample was narrower and higher than the raw clay sample, indicating better crystallinity of the organo-illite/kaolinite than the KA-IL, the values of $\mathrm{d}_{001}$ were increased with functionalization process, the $\mathrm{d}_{001}$ values of KA-IL and KA-IL ${ }_{\text {DMSO }}$ were 0.991 and $1.121 \mathrm{~nm}$, respectively. The results suggest that the physical-chemical properties were optimized with functionalization process. The insoluble impurities such as quartz and feldspar become more intense as the intercalation process. The intensities of (100) and (110) kaolinite-illite reflections were increased and presence of material amorphized not was observed with organofunctionalization process ${ }^{13}$.

Table 2: Percentages of carbon $(\mathrm{C})$, hydrogen $(\mathrm{H})$, and sulfur $(\mathrm{S})$ for natural and modified interstratified.

\begin{tabular}{|c|c|c|c|c|c|}
\hline Sample & $\% \mathrm{C}$ & $\% \mathrm{H}$ & $\% \mathrm{~S}$ & $\mathrm{C} / \mathrm{S}_{\text {calculated }}$ & $\mathrm{C} / \mathrm{S}_{\text {found }}$ \\
\hline KA-IL & 0.0025 & 0.0997 & - & - & - \\
\hline KA-IL $_{\text {DMSO }}$ & 6.9871 & 15.5671 & 3.0220 & 2.3121 & 2 \\
\hline
\end{tabular}

\subsection{Equilibrium and kinetic of adsorption}

From the adsorption isotherms for $\mathrm{Zn}^{2+}$ ions, represented by $\mathrm{C}_{\mathrm{S}}$ versus $\mathrm{N}_{\mathrm{f}}$ plot (Fig. 2a), the theoretical curves were obtained with a non-linear method, as shown in Fig. 2b, whose data were adjusted to the Langmuir, Freundlich, and Sips models. The Langmuir adsorption model can be used to explain the significant capacity of the materials to quantify divalent metal interactions by complexation reactions, the values of determination coefficient, $\mathrm{R}^{2}$, were 0.999 for two adsorption systems (Table 3). The theoretical adsorption models present a significant advantage in comparing the experimental data; it allows quantifying the capacity of retaining cations within the structure of the porous matrix and to evaluate the constant related to the boding energy.

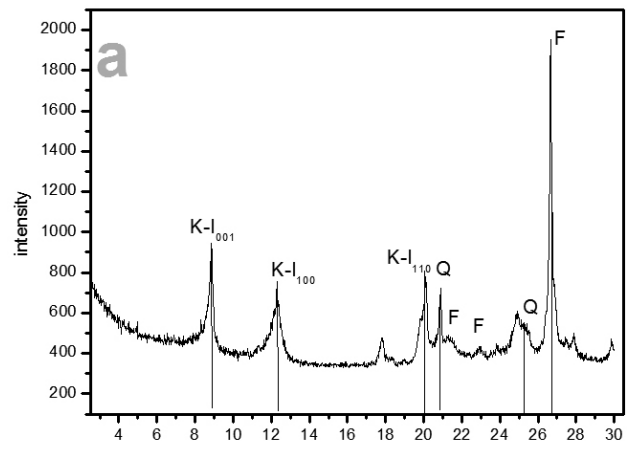

$2 \theta$

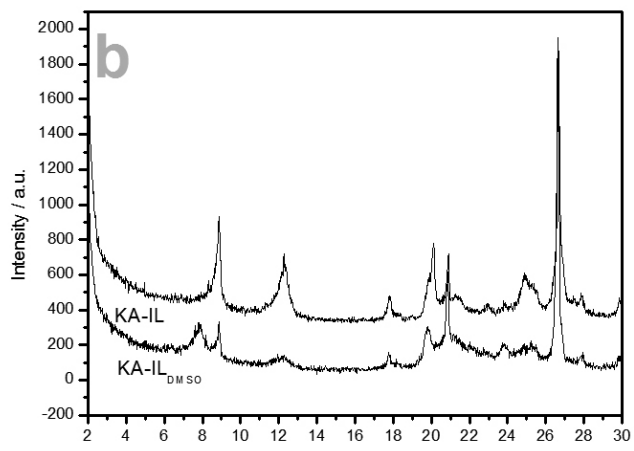

$2 \theta$

Figure 1-Powder X-ray diffraction of the materials: KA-IL with component minerals (a) and KA-IL and KA-IL ${ }_{\text {DMSO }}$ (b).
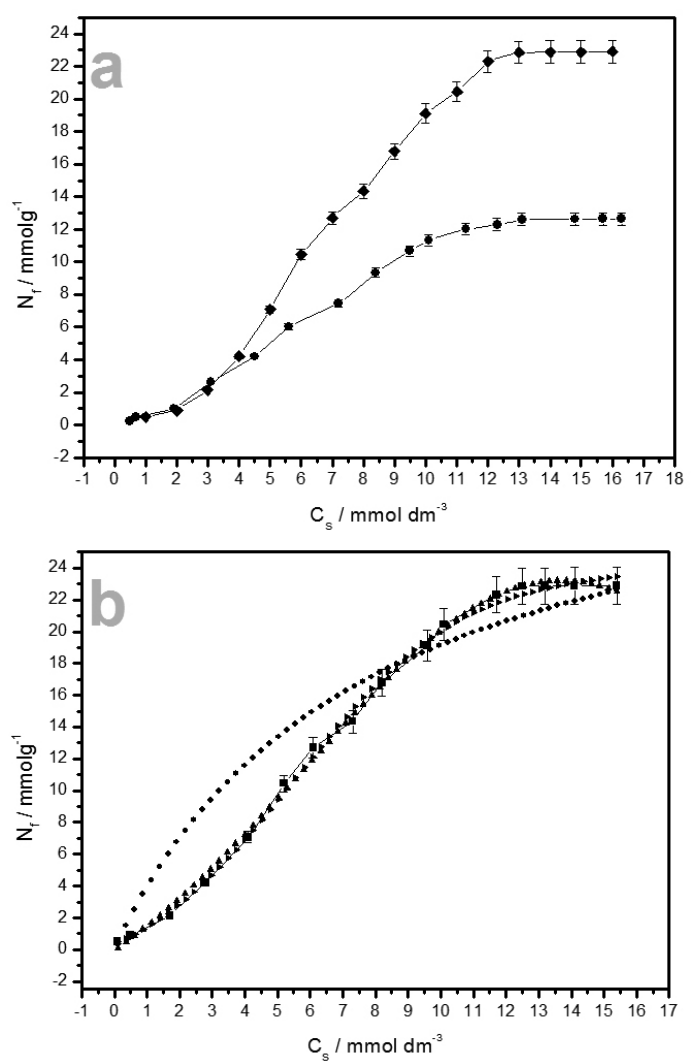

Figure 2-Effect of concentration of zinc adsorption onto clay samples (a), and Isotherms calculated with non-linear method: Sips $\boldsymbol{\nabla}$, Langmuir $\boldsymbol{\Delta}$, and Freundlich $\bullet(b)$. 
Table 3: Isotherms of equilibrium adsorption parameters (at $298 \pm 1$ degree $\mathrm{K}$ and $\mathrm{pH}$ 5.0).

\begin{tabular}{|c|c|c|}
\hline \multirow[t]{2}{*}{ Adsorption models } & \multicolumn{2}{|c|}{ Parameter Values } \\
\hline & KA-IL & KA-IL \\
\hline \multicolumn{3}{|c|}{ Isotherms equilibrium models } \\
\hline \multicolumn{3}{|l|}{ Langmuir } \\
\hline $\mathrm{N}_{\mathrm{L}}\left(\mathrm{mmol} \mathrm{g}^{-1}\right)$ & 12.571 & 22.8776 \\
\hline $\mathrm{K}_{\mathrm{L}}\left(\mathrm{dm}^{3} \mathrm{mmol}^{-1}\right)$ & 0.967 & 0.951 \\
\hline $\mathrm{R}^{2}$ adjusted & 0.999 & 0.999 \\
\hline $\mathrm{F}_{\text {error }}$ & 0.075 & 0.081 \\
\hline \multicolumn{3}{|l|}{ Freundlich } \\
\hline $\mathrm{K}_{\mathrm{F}}\left[\mathrm{mmolg}^{-1}\left(\mathrm{mmoldm}^{-3}\right)_{\mathrm{F}}^{-1 / n}\right]$ & 0.987 & 0.932 \\
\hline $\mathrm{n}_{\mathrm{F}}$ & 1.534 & 1.232 \\
\hline $\mathrm{R}^{2}$ adjusted & 0.971 & 0.871 \\
\hline $\mathrm{F}_{\text {error }}$ & 1.679 & 1.787 \\
\hline \multicolumn{3}{|l|}{ Sips } \\
\hline $\mathrm{N}_{\mathrm{s}}\left(\mathrm{mmol} \mathrm{g}^{-1}\right)$ & 1.561 & 2.544 \\
\hline $\mathrm{K}_{\mathrm{S}}\left(\mathrm{mmoldm}^{-3}\right)^{-1 / n} \mathrm{~s}$ & 1.056 & 1.045 \\
\hline $\mathrm{n}_{\mathrm{s}}$ & 0.851 & 0.982 \\
\hline $\mathrm{R}^{2}$ adjusted & 0.998 & 0.988 \\
\hline $\mathrm{F}_{\text {error }}$ & 0.135 & 0.197 \\
\hline
\end{tabular}

Several kinetic models were investigated for the adsorption of metals from wastewaters by porous materials. The mechanism of adsorption often involves the chemical reaction between reactive groups on the surface materials and the divalent metal. The number of reactive groups can be reinforced by organofunctionalization process. The adsorption experimental data for $\mathrm{Zn}^{2+}$ ions uptake versus contact time for a fixed adsorbent amounts are presented in Fig. 3a, giving identical abrupt increases in adsorption at low times before reaching the plateaus in the experimental isotherms. According to these data, equilibrium is achieved at around 120 and 140 minutes for the systems $\mathrm{Zn}^{2+} / \mathrm{KA}-\mathrm{IL}_{\mathrm{Duso}}$ and $\mathrm{Zn}^{2+} / \mathrm{KA}-\mathrm{IL}$, respectively. However, to be sure of the best adsorption conditions at higher concentrations levels, and to obtain equilibrium at the solid/liquid interface, all of the experiments were carried out within 180 minutes of contact time (Fig. 3). This short time period required to attain equilibrium suggests an excellent affinity of the zinc for these materials, principally in the adsorption process with modified Interstrafied from aqueous solution. When the rate of reaction of an adsorption reaction is controlled by a chemical exchange, pseudo-second order Lagergren model can be better adjusted to the experimental kinetic data, this model is also based on the adsorption capacity of the solid phase ${ }^{15}$, as expressed by Table 4 . Carrying out a set of experiments at constant temperature ( $273 \pm 1$ degree K) and monitoring the amount adsorbed over time, the kinetics of the adsorption process should be identified. The rate of metal uptake during the entire period of adsorption was found to be independent of the initial metal concentration used. The correlation coefficient of the pseudo-second-order rate equation $\left(\mathrm{R}^{2}\right)$ for the non-linear regression was approximately 0.99 , which suggest that the kinetic adsorption can be described by the pseudo-second-order rate equation with a satisfactory approximation of the experimental kinetic curve (Fig. 3b).

Based on the pseudo second-order model, the initial adsorption rate and half-adsorption time are estimated by the following Eqs. 2 and $3^{16}$ :
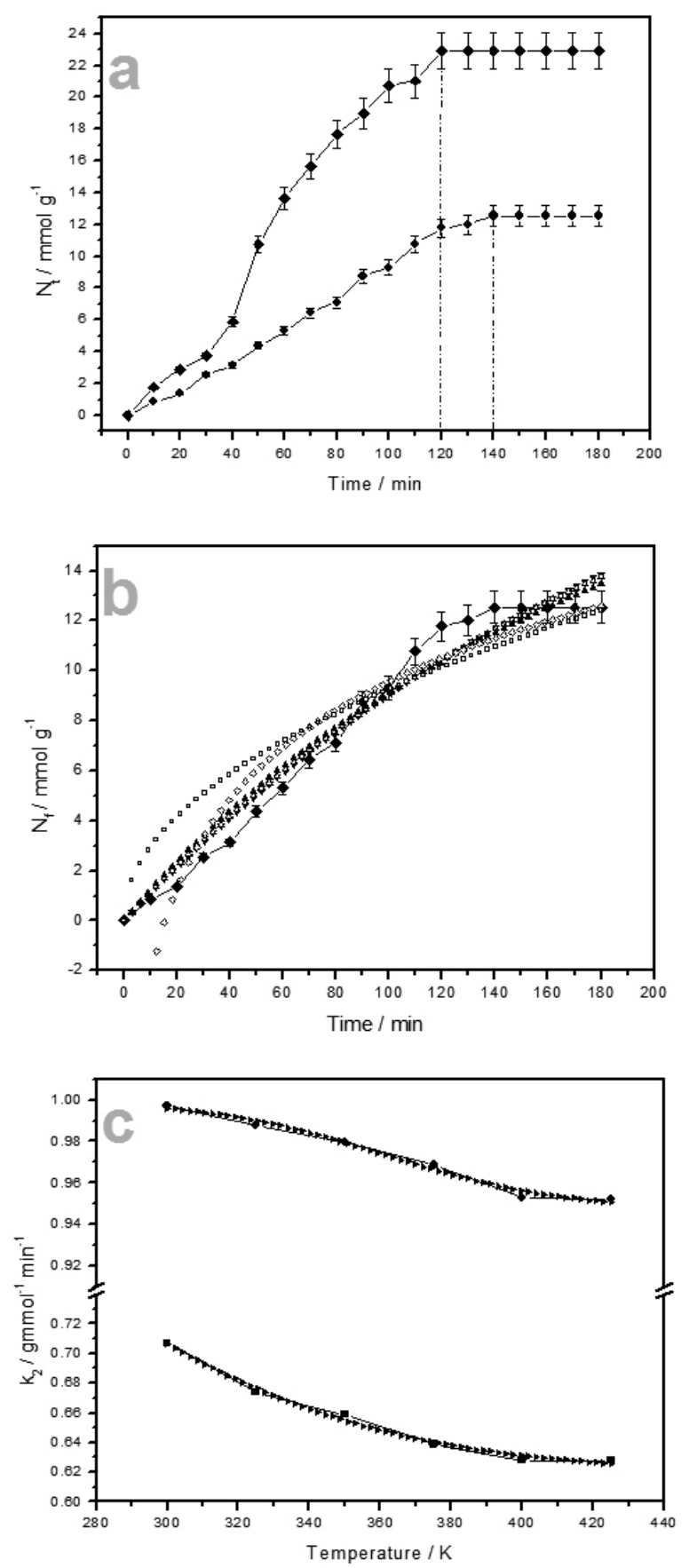

Figure 3- Kinetic curves of zinc adsorption: experimental curves (a), KAIL " and KA-IL $\mathrm{IMSO} \bullet$; theoretical curves (b): pseudo-firth-order $\boldsymbol{\nabla}$, pseudosecond-order $\boldsymbol{\Delta}$, Avrami D, Elovich $\diamond$, and Intra-particle diffusion $\square$ and activation energy calculated by non-linear of Arrhenius equation $>$ (c).

$$
\mathrm{h}=\mathrm{k}_{2} \mathrm{~N}_{\mathrm{fEQ}}^{2}
$$

$$
\mathrm{t}_{1 / 2}=\frac{1}{\mathrm{k}_{2} \mathrm{~N}_{\mathrm{fEQ}}}
$$


Table 4: Isotherms of kinetic adsorption parameters (at $298 \pm 1$ degree $\mathrm{K}$ and $\mathrm{pH}$ 5.0).

\begin{tabular}{|c|c|c|}
\hline \multirow[t]{2}{*}{ Adsorption models } & \multicolumn{2}{|c|}{ Parameter values } \\
\hline & KA-IL & $\mathrm{KA}-\mathrm{IL}_{\mathrm{DMSO}}$ \\
\hline \multicolumn{3}{|l|}{ Avrami } \\
\hline $\mathrm{N}_{\mathrm{t}}\left(\mathrm{mmolg}^{-1}\right)$ & 11.4155 & 20.8923 \\
\hline $\mathrm{k}_{\mathrm{AV}}\left(\min ^{-1}\right)$ & 2.0146 & 3.0124 \\
\hline $\mathrm{n}_{\mathrm{AV}}$ & 0.3784 & 0.5678 \\
\hline $\mathrm{R}^{2}$ adjusted & 0.9679 & 0.9744 \\
\hline $\mathrm{F}_{\text {error }}$ & 0.1563 & 0.1321 \\
\hline \multicolumn{3}{|c|}{ Pseudo-first-order } \\
\hline $\mathrm{N}_{\mathrm{t}}\left(\mathrm{mmolg}^{-1}\right)$ & 12.6934 & 22.5678 \\
\hline$k_{f}\left(\min ^{-1}\right)$ & 1.9845 & 2.6547 \\
\hline $\mathrm{R}^{2}$ adjusted & 0.9876 & 0.9856 \\
\hline $\mathrm{F}_{\text {error }}$ & 0.0654 & 0.0897 \\
\hline \multicolumn{3}{|c|}{ Pseudo-second-order } \\
\hline $\mathrm{N}_{\mathrm{t}}\left(\mathrm{mmolg}^{-1}\right)$ & 12.8711 & 23.0113 \\
\hline $\mathrm{k}_{\mathrm{s}}\left(\mathrm{gmmol}^{-1} \mathrm{~min}^{-1}\right)$ & 0.9961 & 0.7054 \\
\hline $\mathrm{h}\left(\mathrm{mmolg}{ }^{-1} \mathrm{~min}^{-1}\right)$ & 156.8882 & 369.6011 \\
\hline$t_{1 / 2}$ & 0.1130 & 0.0439 \\
\hline $\mathrm{R}^{2}$ adjusted & 0.9987 & 0.9998 \\
\hline $\mathrm{F}_{\text {error }}$ & 0.0087 & 0.0078 \\
\hline \multicolumn{3}{|c|}{ Intra-particle diffusion } \\
\hline $\mathrm{N}_{\mathrm{t}}\left(\mathrm{mmolg}^{-1}\right)$ & 11.5515 & 20.9912 \\
\hline $\mathrm{k}_{\mathrm{ID}}\left(\mathrm{mmolg}^{-1} \min ^{-0.5}\right)$ & 25.3651 & 38.5694 \\
\hline $\mathrm{C}\left(\mathrm{mmolmin}^{-1}\right)$ & 5.7894 & 12.5672 \\
\hline $\mathrm{R}^{2}$ adjusted & 0.9768 & 0.9654 \\
\hline $\mathrm{F}_{\text {error }}$ & 1.9113 & 1.9321 \\
\hline
\end{tabular}

The half-adsorption time $t_{1 / 2}$ is another parameter and is defined as the time required for the adsorption to take up half as much $\mathrm{Zn}^{2+}$ ions as its equilibrium values for three systems. Thus, the initial adsorption rate and half-adsorption time are usually a measure of adsorption rate.

For the determination of activation energy $\mathrm{E}_{\mathrm{a}}\left(\mathrm{kJmol}^{-1}\right)$, for $\mathrm{Zn}^{2+}$ adsorption reactions, the pseudo-second-order rate constant $\mathrm{k}_{\mathrm{S}}\left(\mathrm{gmmol}^{-1} \mathrm{~min}^{-1}\right)$ was expressed as a function of six different temperatures $T^{\mathrm{s}}(298,323,348,373$, 393, and $413 \pm 1$ degree K) by an Arrhenius type relationship (Eq. 4) ${ }^{17}$ :

$$
\mathrm{k}_{\mathrm{S}}=\mathrm{k}_{0}-\exp \left(\frac{\mathrm{E}_{\mathrm{a}}}{\mathrm{RT}}\right)
$$

where $\mathrm{k}_{0}\left(\mathrm{gmol}^{-1} \mathrm{~min}^{-1}\right)$ is the temperature independent factor. From this equation and nonlinear method, the rate constant values of adsorption, $\mathrm{k}_{0}$ and the activation energy values can be calculated, and are presented in Table 5. These values show that the adsorption processes of $\mathrm{Zn}^{2+}$ ions by adsorbent surfaces of materials used in this work are exothermic. These results may be explained by the fact that the adsorption phenomena are exothermic and spontaneous processes in two systems, confirming the conclusion obtained by Van't Hoff method ${ }^{18}$, the values of determination coefficient $\left(\mathrm{R}^{2}\right)$ for both calculated curves were approximately 0.99 . The pseudo-second-order kinetic constant decreased with increasing temperature (Fig. 3c).

\subsection{Evolution of thermodynamic effects of the adsorption}

Change in Gibbs free energy $(\Delta \mathrm{G})$, enthalpy $(\Delta \mathrm{H})$, and entropy $(\Delta \mathrm{S})$ are important thermodynamic parameters that were determined using the following equations (Eqs. 5 and 6) and calculated data obtained plot DG $\left(\mathrm{kJmol}^{-1}\right)$ versus variation of temperature (K) (Fig. 4), taking these values into account ${ }^{19}$ for $\mathrm{Zn}^{2+}$ onto natural and modified interstratified sample are given in Table 5, taking values into account:

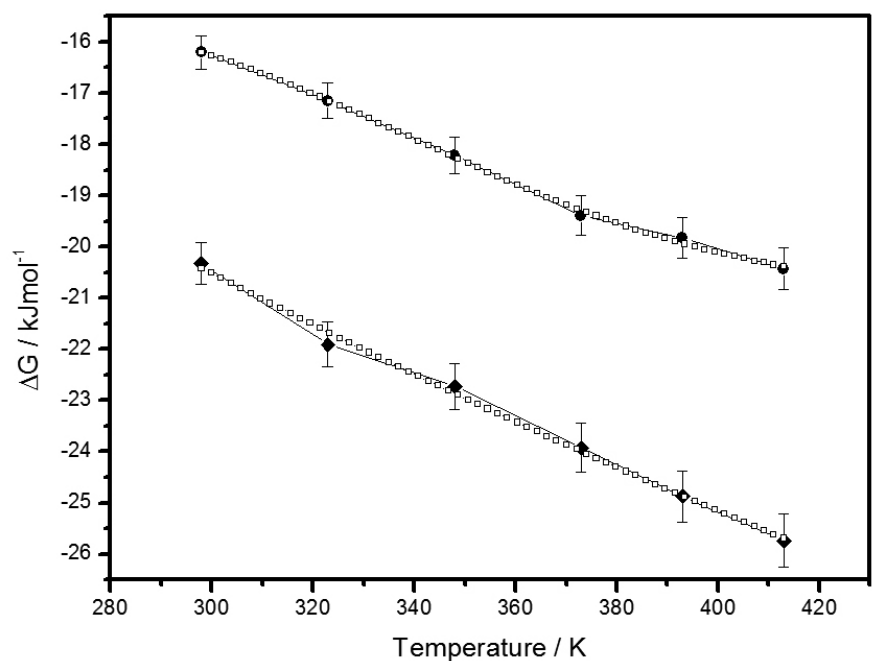

Figure 4- Relationship between Gibbs free energy $(\Delta \mathrm{G})$ and variation of temperature for zinc adsorption for determination of thermal effect of adsorption process onto KA-IL ". and KA-IL $\mathrm{DMSO} \bullet$ through theoretical adsorption curves $\square$.

$$
\Delta \mathrm{G}=-\mathrm{RT} \ln \mathrm{K}_{\mathrm{L}}
$$

where $\mathrm{K}\left(\mathrm{dm}^{3} \mathrm{mmol}^{-1}\right)$ is the equilibrium constant obtained from the Langmuir isotherm equation, $\mathrm{T}(\mathrm{K})$ is the absolute temperature, and $\mathrm{R}$ is the universal gas constant $\left(8.314 \times 10^{-3} \mathrm{kJK}^{-1} \mathrm{~mol}^{-1}\right)$. Eq. 6 relates the energetic of adsorption systems ${ }^{19}$ :

$$
\Delta \mathrm{G}=\Delta \mathrm{H}-\mathrm{T} \Delta \mathrm{S}
$$

The relation between $\mathrm{K}_{\mathrm{L}}$ and the thermodynamic parameters of entropy and enthalpy can be described by Van't Hoff correlation in nonlinear form in the following Eq. $7^{18}$, the result obtained can be observed in Table 5 and Fig. 5.

$$
\mathrm{K}_{\mathrm{L}}=\exp \left[\left(\frac{\Delta \mathrm{S}}{\mathrm{R}}\right)-\left(\frac{\Delta \mathrm{H}}{\mathrm{RT}}\right)\right]
$$

The values of $\Delta \mathrm{H}\left(\mathrm{kJmol}^{-1}\right)$ and $\Delta \mathrm{S}\left(\mathrm{Jmol}^{-1} \mathrm{~K}^{-1}\right)$ were obtained from the slope and intercept of Van't Hoff plots, respectively, five different temperatures $T_{\text {a }}(298,323,348,373$, 393, and 413 \pm 1 degree $\mathrm{K})$ were used for this investigation. From the thermodynamic point of view, the obtained exothermic and positive entropic values establish the set of favorable results for the thermodynamic of $\mathrm{Zn}^{2+}$ - KA-IL $\mathrm{IL}_{\mathrm{DMs}}$ and KA-IL interactions. Thus, the spontaneity of such reactions is expressed by the negative Gibbs free energy with a considerable contribution of the positive entropy. These values suggest that during interactions of $\mathrm{Zn}^{2+}$ ions and reactive sites on the surfaces, the desolvation disturbs the structure of the reaction medium to promote the disorganization of the system and, consequently, leads to an increase in entropy ${ }^{18}$. The positive values of entropy can be increased randomness at the $\mathrm{Zn}^{2+} / \mathrm{KA}-\mathrm{IL}_{\mathrm{DMSO}}$ and $\mathrm{Zn}^{2+} / \mathrm{KA}-\mathrm{IL}$ systems during the adsorption processes. The adsorption is formed of entropic and enthalpic contributions. Data exposed in Table 5 reveals that $\Delta \mathrm{H}$ is significantly rather larger compared to the adsorption energy. The decrease in the Gibbs free energy with rise in temperature shows that the adsorption reaction is favorable at higher temperature. In addition, the values of enthalpy of adsorption for natural and modified clay is lower, this values can indicate that the zinc adsorption process can be controlled by physic and chemical mechanisms ${ }^{20}$. The relationship between free energy Gibbs $(\Delta \mathrm{G})$, enthalpy $(\Delta \mathrm{H})$ and entropy $(\Delta \mathrm{S})$ for two systems can be observed in Fig. 6 
Table 5: Thermodynamic parameters for the zinc adsorption onto natural and modified kaolinite-illite.

\begin{tabular}{|c|c|c|c|c|c|c|c|c|c|c|}
\hline Sample & $\begin{array}{c}\text { Temperature } \\
\text { (K) }\end{array}$ & $\begin{array}{c}\mathrm{K}_{\mathrm{L}} \times 10^{-3} \\
\left(\mathrm{dm}^{3} \mathrm{mmol}^{-1}\right)\end{array}$ & $\begin{array}{c}-\Delta \mathrm{G} \\
\left(\mathrm{kJmol}^{-1}\right)\end{array}$ & $\underset{\mathrm{K}_{0}\left(\mathrm{gmol}^{-}\right.}{\left.{ }^{1} \mathrm{~min}^{-1}\right)}$ & $\begin{array}{c}\mathrm{Ea} \\
\left(\mathrm{kJmol}^{-1}\right)\end{array}$ & $\begin{array}{c}-\Delta \mathrm{G}^{*} \\
\left(\mathrm{kJmol}^{-1}\right)\end{array}$ & $\begin{array}{c}-\Delta \mathrm{H} \\
\left(\mathrm{kJmol}^{-1}\right)\end{array}$ & $\begin{array}{c}\Delta \mathrm{S}\left(\mathrm{Jmol}^{-}\right. \\
\left.{ }^{1} \mathrm{~K}^{-1}\right)\end{array}$ & $\mathrm{F}_{\text {error }}$ & $\mathrm{R}^{2}$ adjusted \\
\hline \multirow{6}{*}{ KA-IL } & 298 & 1.44581 & 16.201 & & & & & & & \\
\hline & 323 & 1.68250 & 17.153 & & & & & & & \\
\hline & 348 & 1.84310 & 18.217 & $0.654 \pm 1$ & $21.50 \pm 02$ & $19.784 \pm 2$ & 8.761 & 47.302 & 0.3243 & 0.9876 \\
\hline & 373 & 1.92441 & 19.392 & & & & & & & \\
\hline & 393 & 2.31622 & 19.826 & & & & & & & \\
\hline & 413 & 2.60612 & 20.431 & & & & & & & \\
\hline \multirow{6}{*}{ KA-IL ${ }_{\text {DMSO }}$} & 298 & 0.27411 & 20.321 & & & & & & & \\
\hline & 323 & 0.28597 & 21.912 & & & & & & & \\
\hline & 348 & 0.38831 & 22.723 & $0.996 \pm 2$ & $23.87 \pm 01$ & $21.361 \pm 3$ & 9.235 & 59.231 & 0.0143 & 0.9923 \\
\hline & 373 & 0.44596 & 23.926 & & & & & & & \\
\hline & 393 & 0.49425 & 24.873 & & & & & & & \\
\hline & 413 & 0.55593 & 25.735 & & & & & & & \\
\hline
\end{tabular}

(*) Gibbs free energy calculated by nonlinear method (plots $\mathrm{K}_{\mathrm{L}}$ versus Temperature).

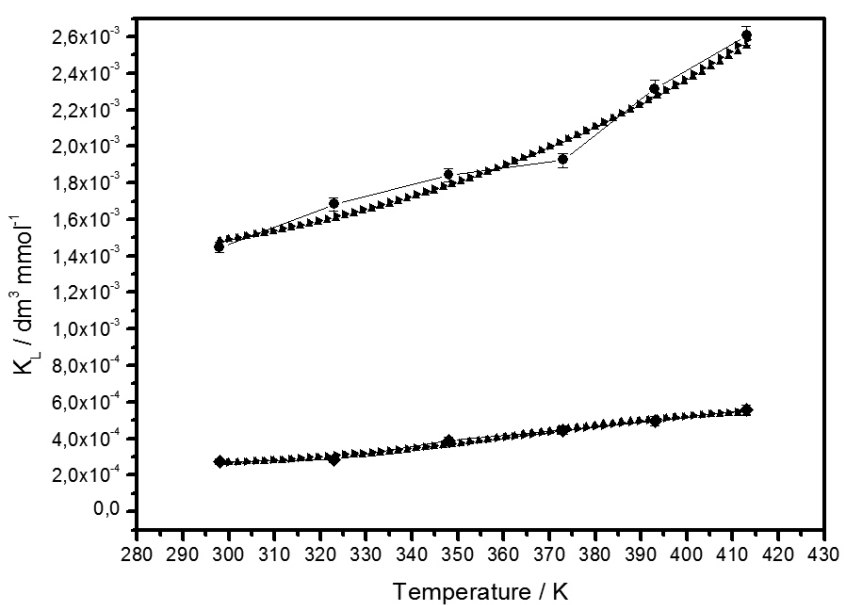

Figure 5- Relationship between $\mathrm{K}_{\mathrm{L}}$ and variation of temperature for the zinc adsorption onto KA-IL " and KA-IL ${ }_{\text {DMso }} \bullet$ for determination of Gibbs free energy $(\Delta \mathrm{G})$ through theoretical adsorption curves by nonlinear method $\square$

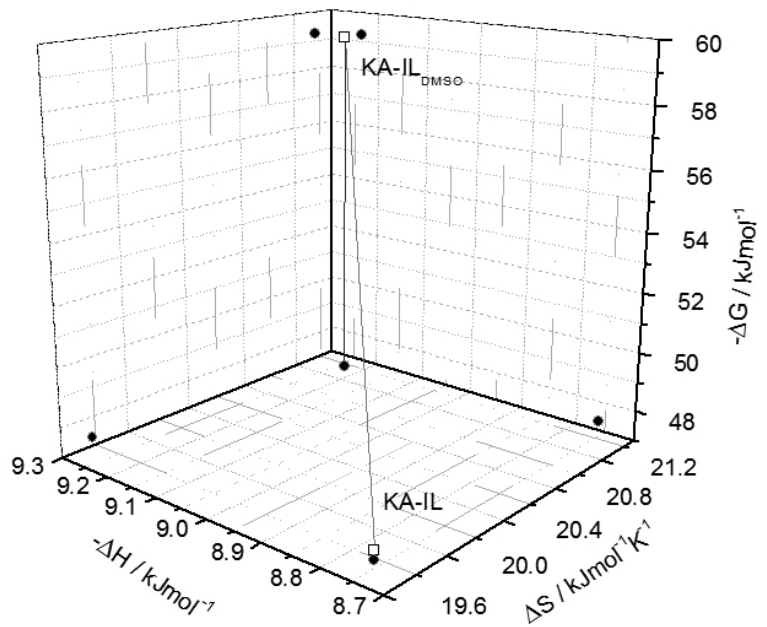

Figure 6- Relationship between free energy Gibbs $(\Delta \mathrm{G})$, enthalpy $(\Delta \mathrm{H})$ and entropy $(\Delta S)$ for zinc adsorption.

\section{CONCLUSION}

The efficiency of adsorption process with the raw and hybrid geological material used in this study depends not only on the chemical and physical properties of the adsorbate, but also on the composition of medium. Thermodynamic effects, concentration of medium and time of contact metal-clay surface are one or more selected parameters investigated as the characteristics of aqueous medium affecting material capacities. A summary of the present investigation is as follows:

(i) The removal of $\mathrm{Zn}^{2+}$ by KA- $\mathrm{IL}_{\text {DMSo }}$ and KA-IL is a complex phenomenon, principally in the heterogeneous surfaces, such as KA$\mathrm{IL}_{\mathrm{DMSO}}$. The pseudo second-order model provided the best correlation of the experimental kinetic data. Measured values of model constants indicated significant differences in the curve shapes and adsorption capacities regarding natural and organoclay in reaction with zinc metallic cation.

(ii) The adsorption results were confirmed through stable complexes formed between cations and reactive groups disposed on the natural and organoclay surfaces, whose behaviour was checked by the thermodynamic values obtained by Van't Hoff correlation at the solid/liquid interface to give favourable sets of data. Thermodynamic values calculations showed that the $\mathrm{Zn}^{2+}$ ions adsorption process by materials has an exothermic and spontaneous nature, such as exothermic enthalpy, negative Gibbs free energy, and positive entropic values. The efficiency of adsorption process of $\mathrm{Zn}^{2+}$ on natural and modified interstratified samples were obtained by chemical and physical mechanisms, these mechanisms can be optimized by the reactive species in the clay surfaces, such as hydroxyl groups and sulfur atoms. The spontaneity of adsorption process can be explained and represented energetically through of the linear equations: $\mathrm{y}=-5.02045 \pm 3.773 \times 10^{-2} \mathrm{x}$ and $\mathrm{y}=-6.81613 \pm 4.592 \times 10^{-2} \mathrm{x}$ for KI-IL and KI-IL ${ }_{\text {DMSO }}$, respectively.

(iii) In conclusion, all thermodynamic values are favourable, and exothermic enthalpy, negative free Gibbs energy and positive entropy data

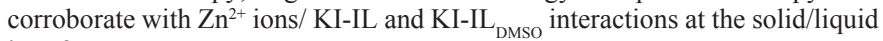
interface.

(iv) Actuality a wide variety of adsorbent materials is utilized for the adsorption of a broad range of pollutants; the ideal adsorbent mandatorily should be interesting characteristics for industrial and environmental applications, in this context, is possible conclude that the clay and organoclays employed are quite economic than commercially available adsorbents and that were applied industrially for batch and dynamic flow method. Temperature, thermodynamic parameters, effect of concentration variation, and contact time will be important parameters affecting the adsorption capacity in the real application in the removal process by these materials in future.

\section{ACKNOWLEDGEMENTS}

The authors are grateful to MCT, CNPq, and CAPES for financial supports and fellowships. 


\section{REFERENCES}

1. B. S. Batlokwa, L. Chimura, Z. Tshentu, E. Cukrowska, N. Torto, Water SS. 38, 255, (2012)

2. R. Souag, D. Touaibia, B. Benayada, A. Boucenna, European Journal of Scientific Research 35, 416, (2009)

3. J. C. Echeverria, E. Churio, J. Garrido, Clays Clay Miner. 50, 614, (2002)

4. A. Mellah, S. Chegrouche, Water Res. 31, 621, (1997)

5. O. Yavuz, Y. Altunkaynak, F. Guzel, Water Res. 37, 948, (2003)

6. M. F. Brigatti, C. Lugli, L. Poppi, App. Clay Sci. 16, 45, (2000)

7. S. Sen Gupta, K. G. Bhattacharyya, Physical Chemistry Chemical Physics 14, 6698, (2012)

8. L. R. Avila, E. H. de Faria, K. J. Ciuffi, E. J. Nassar, P. S. Calefi, M. A. Vicente, R. Trujillano, J. Colloid Interface Sci. 341, 186, (2010)

9. A. Chaudhari, C. V. Kumar, Micropor. Mesopor. Mater. 77, 175, (2005)
10. P. Zhang, Y. Wang, G. S. Zhu, Z. Shi, Y. L. Liu, H. M. Yuan, W. Q. Pang, J. Solid. State Chem. 154, 368, (2000)

11. B. Royer, N. F. Cardoso, E. C. Lima, J. C. P. Vaghetti, N. M. Simon, T. Calvete, R. C. Veses, J. Hazard. Mater. 164, 1213, (2009)

12. V. S. O. Ruiz, C. Airoldi, Thermochim. Acta 420, 73, (2004)

13. H. Komine, Engineer. Geology 114, 123 (2010)

14. C. G. Pope, J. Chem. Educ. 74, 129 (1997)

15. E. Zeynep, N. A. Filiz, Desalination 194, 1 (2006)

16. Y. S. Ho, G. McKay, Process Biochem. 39, 759 (2004)

17. N. Yeddou, A. Bensmaili, Desalination 185, 499 (2005)

18. H. Koyuncu, A. R. Kul, A. Çalimli, N. Yildz, H. Ceylan, LWT 40, 489, (2007)

19. E. Malkoc, Y. Nuhoglu, J. Hazard. Mater, B 127, 120, (2005)

20. S. S. Tahir, N. Rauf, J. Chem. Thermodyn. 35, 2003, (2003) 